\title{
A música sacra no reinado de Leopoldo I (1658-1705) ${ }^{1}$
}

\section{Sacred music in Leopold I's reign}

Caio Amadatsu Griman ${ }^{2}$ Universidade Estadual Paulista - UNESP caiogriman@gmail.com

Dorotéa Machado Kerr ${ }^{3}$ Universidade Estadual Paulista - UNESP dorotea.kerr@unesp.br 


\section{Resumo}

Quando Leopoldo I foi coroado imperador do Sacro Império Romano-Germânico, em 1658, a maior parte da Europa ainda estava em processo de recuperação econômica decorrente da chamada "crise geral do século XVII". Dentro deste contexto, coube a Leopoldo e aos demais membros da Casa de Habsburgo a tarefa de reorganização e de solidificação do absolutismo na Áustria. Para tal fim, o imperador encontrou na música sacra uma ferramenta eficaz de convencimento, propaganda e exibição do poder imperial. Neste trabalho procuramos demonstrar o papel das produções musicais ligadas às atividades da Contrarreforma no reinado de Leopoldo I. Inicialmente, discorremos acerca da criação religiosa de Leopoldo, assim como sobre seu interesse particular pela música e pela composição. Em seguida, examinamos a influência da imperatriz viúva Leonor de Gonzaga-Nevers (madrasta de Leopoldo I) para o desenvolvimento da música austríaca, principalmente em relação à sua participação no estabelecimento do sepulcro em Viena.

Palavras-chave: Música sacra; Contrarreforma; Leopoldo I; Viena; Áustria.

\section{Abstract}

When Leopoldo I was crowned emperor of the Holy Roman Empire in 1658, most of Europe was still in the process of economic recovery due to the so-called "general crisis of the 17th century". Therefore, Leopoldo and the other members of the House of Habsburg were tasked with the reorganization and solidification of absolutism in the Austrian domains. To this end, the emperor found in sacred music an effective tool for convincing, advertising and displaying imperial power. This article aims to show the role of musical productions linked to the activities of the Counter-Reformation in Leopoldo I's reign. Initially, will be examined Leopoldo's religious education, as well as his particular interest in music and composition. There follows a discussion about the influence of the widowed empress Leonora de Gonzaga-Nevers (Leopoldo l's stepmother) in the development of Austrian music, mainly in relation to her participation in the establishment of the sepulcro in Vienna.

Keywords: Sacred music; Counter Reformation; Leopold I; Vienna; Austria.

\footnotetext{
$1 \quad$ Este trabalho foi realizado com o apoio financeiro da Fundação de Amparo à Pesquisa do Estado de São Paulo - Fapesp (processo ${ }^{\circ}$ 2019/12280-4). As opiniões, hipóteses e conclusões ou recomendações expressas neste material são de responsabilidade do autor e não necessariamente refletem a visão da Fapesp.

2 Graduando no curso de Bacharelado em Composição na Universidade Estadual Paulista Júlio de Mesquita Filho (Unesp) e desenvolve o supra citado projeto de iniciação de científica sob orientação de Dorotéa Machado Kerr, Professora Adjunta (Livre-docente II) do Instituto de Artes da UNESP, Departamento de Música.

3 Professora Adjunta do Instituto de Artes da UNESP, Departamento de Música. Livre-docente II em Instrumento Órgão e História da Música pela Universidade Estadual Paulista UNESP. Doutorado em Música/Órgão pela Indiana University (1989), Estados Unidos. Na UNESP foi Coordenadora do Programa de Pós-graduação em Música do IA/UNESP de 2002-2007, Presidente da Comissão de Pesquisa do Instituto de Artes da UNESP e Membro do Comitê Central PIBIC/CNPq da UNESP. Foi presidente da Associação Brasileira de Organistas 2015-2018. Foi bolsista PQ2 do CNPQ de 2010 a 2013; e de 2013 a 2016.
} 


\title{
Introdução
}

O século XVI foi marcado por inúmeras transformações que alteraram profundamente o desenvolvimento da Europa. O advento do protestantismo, em especial, acabou gerando grandes tensões em praticamente todo o continente. Dentro deste contexto, os membros da Casa de Habsburgo, tanto em seu ramo espanhol quanto austríaco, tornaram-se alguns dos principais agentes da Contrarreforma. Durante a primeira metade do século XVI, por exemplo, o imperador Carlos V - único monarca a ter governado simultaneamente a Espanha e o Sacro Império Romano-Germânico - esteve envolvido em inúmeros conflitos militares contra os protestantes alemães, destacadamente na Guerra dos Camponeses (1524-1525) e na Guerra de Esmalcalda (1546-1547).

Entretanto, apesar de todas estas tensões, os principais monarcas do século XVI, como Maximiliano II do Sacro Império Romano-Germânico, Henrique III da França e Filipe II da Espanha, conseguiram contornar esses problemas e manter um crescimento econômico constante até, pelo menos, o início da Guerra dos Trinta Anos, em 1618. Assim sendo, ainda que as disputas entre os adeptos da Reforma e da Contrarreforma continuassem intensificando o ambiente bélico existente, a estabilidade econômica pôde assegurar, por um longo período, uma tranquilidade política para a maior parte das monarquias europeias, proporcionando, como consequência, a possibilidade de alargamento do Estado absolutista.

Dentro deste contexto, muitos teóricos políticos católicos passaram a ser alguns dos mais importantes apologistas do poder absolutista. Segundo Weaver,

\begin{abstract}
A fervorosa recatolicização não serviu apenas à Igreja; também estava intimamente relacionada ao crescimento do absolutismo político e à consolidação da autoridade central da dinastia [de Habsburgo]. [...] todos os teóricos políticos católicos dos séculos XVI e XVII, pelos quais os Habsburgos foram fortemente influenciados, concordaram que a lealdade política dos súditos poderia ser assegurada com mais eficácia se todos seguissem uma única fé cristã; a coexistência de múltiplas confissões em um único reino, argumentou-se, semearia nada além de discórdia e rebelião. (WEAVER, 2006, p.365). ${ }^{4}$
\end{abstract}

O jesuíta alemão Adam Contzen (1571-1635), por exemplo, ganhou notoriedade ao defender, em sua obra Politicorum libri decem, a existência de um governo forte como única esperança de combate real ao caos político e religioso da época. Segundo Robert Bireley (1990, p.138), "o Politicorum libri decem logo se tornou uma influente referência para os Estados católicos, especialmente na Europa Central, uma posição que a obra manteria até o início do século XVIII". ${ }^{5}$

\footnotetext{
$4 \quad$ Original: "The fervent re-Catholicization did not serve only the Church; it was also intimately related to the growth of political absolutism and the consolidation of the dynasty's central authority. [...] Catholic political theorists of the sixteenth and seventeenth centuries, by whom the Habsburgs were strongly influenced, all agreed that the political allegiance of one's subjects could be assured most effectively if they all adhered to a single Christian faith; the coexistence of multiple confessions in a single realm, it was argued, could sow nothing but discord and rebellion" (WEAVER, 2006, p.365). Tradução nossa, como todas as traduções ao longo deste texto.

$5 \quad$ Original: "The Ten books soon became an influential blueprint for a Catholic state, especially in Central Europe, a position it would hold into the early eighteenth century" (BIRELEY, 1990, p.138).
} 
A compreensão de pensadores como Adam Contzen de que a piedade e as virtudes católicas eram bases fundamentais para o sucesso de um monarca logo tornou-se um dos pilares centrais do pensamento político da Monarquia de Habsburgo. Isto pois a Casa Imperial acreditava ser a dinastia católica par excellence e que, portanto, tinha a responsabilidade especial de defender, tanto no âmbito militar quanto no teológico, o verdadeiro cristianismo contra as heresias dos príncipes protestantes.

É neste ambiente político e religioso que o termo pietas austriaca passou a ser amplamente utilizado por autores como Didaco da Lequile, Johann Ludwig Schönleben e Adlbert Czerwenka em referência à piedade pessoal dos monarcas do Sacro Império Romano-Germânico. De acordo com Anna Coreth, "o significado especial desse termo se baseava na convicção de que Deus dera à casa da Áustria uma certa missão para o império e a igreja, por causa dos méritos religiosos de seus ancestrais, ou, mais particularmente, do grande ancestral Rudolfo de Habsburgo" (CORETH, 2004, p.xxii). ${ }^{6}$

Todavia, a maioria destes debates teológicos dificilmente alcançava a maior parte da população, pois, mesmo entre os poucos nobres letrados, apenas uma minoria restrita realmente conhecia latim suficientemente para compreender textos mais complexos. Desse modo, os membros da Casa de Habsburgo e os demais agentes da Contrarreforma encontraram na patronagem de obras de arte um meio mais eficaz para divulgação extensiva de suas principais concepções políticas e religiosas. Em grande medida, "os Habsburgos foram mais capazes de fortalecer sua autoridade através da promoção de uma cultura cortesã especial dominada pela fé católica" (WEAVER, 2016, p.3).7

Ainda que as produções culturais medievais e renascentistas também estivessem intimamente relacionadas à patronagem da nobreza e da lgreja, é possível dizer que, após o advento da Reforma Protestante e, em seguida, da realização do Concílio de Trento, esta relação foi profundamente modificada. Se por um lado os reformados passaram a rejeitar o culto às imagens, os católicos, ao reafirmarem a antiga relação entre arte e fé, ampliaram de modo significativo o papel dos artistas nas cortes e nas igrejas por toda a Europa. Porém, ao mesmo tempo, os artistas do período também perderam grande parte da autonomia para a realização de suas obras, pois a Igreja e os patronos passaram a interferir mais intimamente em possíveis polêmicas teológicas, assim como em decisões estéticas.

Esta relação entre arte, Contrarreforma e política pode ser observada, por exemplo, no quadro "Ato de devoção de Rudolfo I de Habsburgo" (Fig. 1), elaborado em 1625 pelo pintor flamengo Peter Paul Rubens (1577-1640). Por meio desta pintura, Rubens narra o momento em que Rudolfo I - primeiro Habsburgo a ser coroado imperador - presenteia com seu cavalo, por reverência à eucaristia, um padre que estava viajando a pé enquanto carregava a hóstia. De acordo com Anna Coreth, os eclesiásticos e os teóricos

\footnotetext{
$6 \quad$ Original: "the special meaning of this term was based on the conviction that God had given the house of Austria a certain mission for the empire and the church, because of the religious merits of its ancestors, or, more particularly, of the great ancestor Rudolph of Habsburg" (CORETH, 2004, p.xxii).

$7 \quad$ Original: "the Habsburgs were best able to strengthen their authority through the promotion of a distinctive court culture dominated by the Catholic faith" (WEAVER, 2016, p.3).
} 
políticos germânicos do período barroco acreditavam que esta aliança histórica entre a dinastia Habsburgo e a pietas eucharistica (entendida aqui como "fé na eucaristia") era uma das principais fontes de poder dos imperadores austríacos. Desse modo, por ser considerado um dos principais eventos da história da Casa de Habsburgo, esse episódio passou a ser amplamente retratado por diversos artistas ao longo de todo o século XVII.

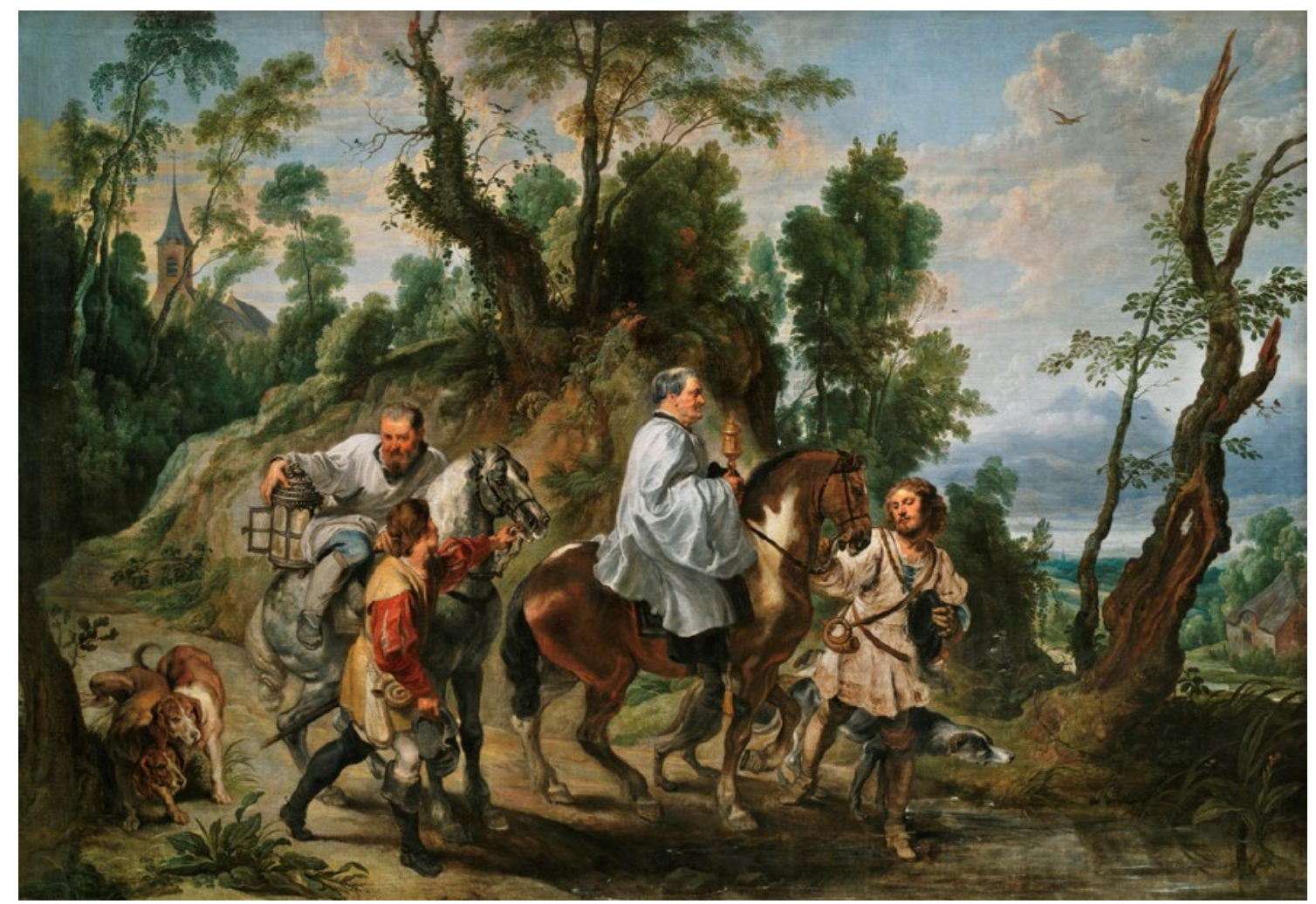

Fig. 1: RUBENS, Peter Paul; WILDENS Jan. Ato de devoção de Rudolfo I de Habsburgo. c. 1625. Pintura, óleo sobre tela, 199 × 286 cm. Museo del Prado, Madrid.

Apesar da importância inegável da pintura para a difusão dos princípios da Contrarreforma, nos territórios germânicos a música sacra acabou se tornando a principal forma de produção artística tanto entre luteranos quanto católicos. Esta preferência pela música pode ser observada, por exemplo, na recusa do reitor do Colégio de Viena, padre Nicolau Lanoy, a interromper as atividades musicais da instituição, a despeito das inúmeras advertências de Ignacio Loyola (1441-1556). Em uma carta de 1554, Loyola ordenou:

[...] que se cesse imediatamente de cantar as missas e matinas e se adapte ao nosso procedimento, ou pelo menos, se não the parecer conveniente que isso ocorra subitamente, que isso seja feito aos poucos, de modo que em três meses e aos mais tardar seis meses, isso tenha sido cumprido. (LOYOLA, 1554 apud HOLLER, 2016, p.144).

Todavia, a prática musical no Colégio de Viena, assim como em outras instituições jesuíticas espalhadas pela Áustria e Alemanha, continuou regularmente até a expulsão dos jesuítas em 1782 (em consequência de uma série de reformas drásticas no intuito de remodelar a Monarquia de Habsburgo em conformidade com os ideais iluministas). De acordo com Pamela Potter, 
A ideia de um Estado-nação alemão teve de superar uma longa história de fragmentação política e diferenças regionais, enquanto a música representava uma forma de expressão artística que todos os alemães podiam partilhar. Em todas as regiões de fala alemã, a aristocracia e o mecenato estatal mantiveram, por muito tempo, pródigas instituições musicais, alavancando a carreira de alguns dos mais influentes compositores, maestros e intérpretes. (POTTER, 2015, p.xviii).

Ademais, a música sacra, diferentemente de outras produções seculares, como a ópera, possuía um potencial menor de gerar grandes polêmicas. Segundo Andrew Weaver,

Muitas outras mídias, especialmente as mais efêmeras, como gravuras e medalhas, também poderiam assumir vários significados, dependendo do contexto em que foram recebidas. A música sacra, no entanto, tinha um contexto narrativo, assim como seus sistemas simbólicos, seguro dentro da liturgia estabelecida há muito tempo pela Igreja Católica. (WEAVER, 2016, p.41). ${ }^{8}$

Outra vantagem no uso da música sacra era a possibilidade de alcançar um grande número de pessoas das mais diferentes origens por meio de uma única peça. Isto pois, enquanto um plebeu iletrado podia experienciar uma determinada performance de maneira puramente passiva, um nobre cortesão que conhecesse bem o latim e tivesse a capacidade de reconhecer os mais variados dispositivos composicionais aplicados na peça poderia ter uma escuta muito mais ativa, compreendendo uma gama muito maior de significação dentro da obra.

Desse modo, na virada do século XVI para o século XVII, foi possível observar um crescimento contínuo das atividades musicais ligadas à Casa de Habsburgo e à Igreja católica. Entretanto, após a eclosão da Guerra dos Trinta Anos, a Europa entrou em um período de aproximadamente quarenta anos marcado por uma grave crise econômica e por grandes mudanças socioculturais. Segundo Lawrence Bennett, "As restrições financeiras impostas pela Guerra dos Trinta Anos impediram os Habsburgos de reproduzir o esplendor das óperas às quais as princesas de Mântua estavam acostumadas" (BENNETT, 2013, p.27). ${ }^{9}$ De modo semelhante, ainda que o imperador Fernando III tenha conseguido manter os músicos empregados na capela imperial durante a maior parte da guerra, quando Viena foi sitiada pelas tropas suecas, em 1645, o número de musicistas teve de ser reduzido de noventa para trinta. ${ }^{10}$

Quando o crescimento econômico foi retomado, a partir da década de 1660, a Europa estava totalmente transformada: a França havia superado a Espanha como principal potência política; a monarquia havia sido derrubada e, em seguida, restaurada na Inglaterra (ainda que com os poderes reais drasticamente reduzidos); e a possibilidade depending on the context in which they were received. Sacred music, however, had a secure narrative context within the long-established liturgy of the Catholic Church and its equally long-established symbolic systems. [...] imperial composers were able to ingeniously craft multivalent sacred works that simultaneously served liturgical, devotional, and political ends" (WEAVER, 2016, p.41).

$9 \quad$ Original: "The financial restraints imposed because of the Thirty Years' War prevented the Habsburgs from actually reproducing the costly splendor of the operas to which the Mantuan princesses were accustomed" (BENNETT, 2013, p.27). 
de unificação e formação de um Estado absolutista alemão sob o comando da Casa de Habsburgo havia sido praticamente extinta.

Destarte, quando Leopoldo I foi coroado imperador do Sacro Império Romano-Germânico, em 1658, recaiu sobre ele a difícil tarefa de reestruturação e reorganização das atividades musicais na Monarquia de Habsburgo. Todavia, apesar de todas as dificuldades envolvidas, o monarca austríaco conseguiu, como veremos a seguir, realizar esta tarefa com grande sucesso, transformando Viena, ao final de seu reinado, em um dos principais centros musicais da Europa. Segundo Somerset, "Pode-se dizer que a escola clássica vienense deveu sua origem em grande parte ao incentivo, patrocínio e prática da música pelos Habsburgos" (SOMERSET, 1949, p.204). ${ }^{11}$

\section{Leopoldo I e a música sacra}

Quando Leopoldo nasceu, em junho de 1640, a Guerra dos Trinta Anos ainda era tratada pelos membros da Casa de Habsburgo com grande otimismo, e, apesar da entrada da França no conflito, a maior parte dos cortesãos de Viena acreditava que as tropas de Fernando III ainda sairiam vitoriosas. Neste período, o irmão mais velho de Leopoldo, Fernando IV, era esperado para suceder seu pai e assumir o trono do Sacro Império Romano-Germânico, garantindo assim a continuação da dinastia de Habsburgo no comando do império. Desse modo, enquanto Fernando IV teve sua criação planejada para assumir a coroa imperial, Leopoldo foi educado pelo jesuíta Johann Eberhard Nithard para seguir, assim como seu tio Leopoldo Guilherme, uma carreira eclesiástica.

Entretanto, quando Fernando III faleceu, em 1657, as expectativas que a aristocracia austríaca tinha no início da década de 1640 haviam sido totalmente desfeitas. Tendo de lutar em duas frentes - ao oeste contra os franceses e ao norte contra os suecos -, as tropas imperais foram derrotadas em seguidas batalhas até o fracasso definitivo das forças austríacas em 1648. Além disso, um ano após ser eleito rei dos romanos e, conjuntamente, futuro imperador, Fernando IV faleceu, em 1654, por conta de complicações médicas relacionadas à varíola.

Apesar de ter passado seus primeiros quatorze anos de vida estudando para se tornar um clérigo, Leopoldo I foi eleito, em 18 de julho de 1658, imperador do Sacro Império Romano-Germânico. Por conta de sua educação, o monarca austríaco ficou conhecido em toda a Europa por ser um homem bastante culto e religioso, sendo fluente em alemão, latim, italiano, francês e espanhol. A religiosidade de Leopoldo, por exemplo, foi descrita em 1661 pelo embaixador veneziano, Aluise Molin, da seguinte maneira:

A piedade e a bondade desse jovem príncipe não são credíveis. Ele confessa todos os domingos. [...] Ele não tem nenhuma sombra imaginável de vícios, na verdade ele os detesta, e todas as suas inclinações são à virtude e à bondade de sua natureza. [...] Durante a quaresma três dias da semana são destinados às

11 Original: "It may truly be said that the Viennese classical school owed its origin in large part to the encouragement, patronage and practice of music by the Habsburgs" (SOMERSET, 1949, p.204). 
atividades na capela, e em um dia mais a imperatriz introduziu o Oratório ao uso de Roma. (MOLIN, 1661 apud FIEDLER, 1867, p.49). ${ }^{12}$

Por conta deste caráter profundamente religioso, Leopoldo I se comprometeu diretamente com a causa da Contrarreforma, envolvendo-se, em especial, com inúmeras atividades da Companhia de Jesus. Dessa forma, o reinado de Leopoldo foi marcado por um processo contínuo de recatolização da população austríaca e de combate às demais confissões. Em março de 1670, por exemplo, o monarca decretou a expulsão dos judeus de Viena e do resto da Áustria. O notável sucesso das práticas associadas à Contrarreforma na segunda metade do século XVII esteve intimamente relacionado ao fato de que, se por um lado a Paz de Vestefália (tratado que decretou o final da Guerra dos Trinta Anos) havia dado fim a qualquer possibilidade de dominação efetiva dos territórios germânicos, por outro ela também havia ampliado o direito do imperador em impor o catolicismo em seus domínios. ${ }^{13}$ Segundo Charles Ingrao (2005, p.61):

De fato, se Leopoldo prosseguiu com vigor um aspecto do processo de construção do Estado, foi a continuação, assim como seus antecessores, da aplicação da uniformidade religiosa, que ele também visualizou como um teste decisivo de lealdade à monarquia. Durante o seu reinado, os jesuítas continuaram a dominar as instituições de ensino superior da monarquia. ${ }^{14}$

Os jesuítas, ao longo do século XVII, além de terem educado os principais membros da elite eclesiástica austríaca, também foram responsáveis diretos na formação política de Leopoldo, assim como no desenvolvimento de suas preferências teológicas e estéticas. Outrossim, tendo recebido uma ampla educação humanista, com instruções sobre história, astronomia, filosofia, literatura e arte, Leopoldo acabou desenvolvendo um interesse especial pela composição musical. Durante sua infância e adolescência, o monarca austríaco teve aulas regulares de órgão, flauta e composição com os mais renomados musicistas de Viena, como os irmãos Markus e Wolfgang Ebner e o então mestre de capela Antonio Bertali. Segundo o embaixador Nicolò Sagredo, "Seus exercícios são Igreja, Música e Caça" (SAGREDO, 1665 apud FIEDLER, 1867, p.115). ${ }^{15}$

Devido a este particular envolvimento de Leopoldo com a música e com o catolicismo, o monarca chegou a compor inúmeras peças religiosas, abrangendo praticamente toda a extensão do repertório sacro: ofertórios, hinos devocionais, motetos, missas, salmos, peças dramáticas (como oratório e cantata) e réquiens. Apesar de grande parte destas obras não ter sobrevivido ao tempo, cerca de 79 composições religiosas

\footnotetext{
12 Original: "La pietà, e bontà di questo giouine Precipe non è credibile. Egli si confessa ogni domenica. [...] Non hà immaginabile ombra di vitio, mà anzi l'abborrisse, e tutte le sue inclinationi sono alla virtù, et alla bontà di sua natura portate. [...] La Quaresima tre giorni della settimana tiene Capella, et in un giorno di più hà I'Imperatrice introddotto gli Oratotij all' uso di Roma" (MOLIN, 1661 apud FIEDLER, 1867, p.49).

13 Segundo o princípio cujus regio eius religio, reafirmado na Paz de Vestfália, a religião oficial de uma determinada região do Sacro Império Romano-Germânico seria definida pela religião de seu governante.

14 Original: "Indeed, if Leopold pursued one aspect of the state-building process with vigor, it was in continuing his predecessors' enforcement of religious uniformity, which he too visualized as a litmus test of loyalty to the monarchy. During his reign the Jesuits continued to tighten their grip over the monarchy's institutions of higher education" (INGRAO, 2005, p.61).
}

15 Original: "Li suoi essercitij sono Chiesa, Musica, e Caccia" (SAGREDO, 1665 apud FIEDLER, 1867, p.115). 
são atribuídas ao imperador. ${ }^{16}$ Segundo Lawrence Bennett, "em vista de sua preparação inicial para uma carreira eclesiástica, não surpreende que, como compositor, ele [Leopoldo] tenha dedicado uma quantidade considerável de sua atenção à música sacra" (BENNETT, 2013, p.44). ${ }^{17}$

As composições de Leopoldo I foram frequentemente executadas publicamente pelos músicos da capela imperial, principalmente em ocasiões especiais, como casamentos, festas religiosas e funerais. Em 1673, por exemplo, em decorrência da morte de sua sobrinha e esposa Margarida Teresa de Habsburgo, Leopoldo compôs a peça Missa pro defunctis (W11) para 5 vozes, 4 violas da gamba, 2 cornetti muti, 3 trombones, violoncelo e órgão. Ao observar o trecho de 22 compassos selecionado abaixo (Fig. 2), pode-se atestar a capacidade do monarca em assimilar diversos procedimentos composicionais típicos do estilo veneziano, principalmente em relação ao uso de contrastes, como a justaposição de compassos binários e ternários, as variações entre tutti e solo e o uso tanto de texturas homofônicas quanto imitativas.

\footnotetext{
16 Somerset (1949, p.210).

17 Original: "In view of his early preparation for an ecclesiastical career, it is not surprising that as a composer he devoted a considerable amount of his attention to sacred music" (BENNETT, 2013, p.44).
} 


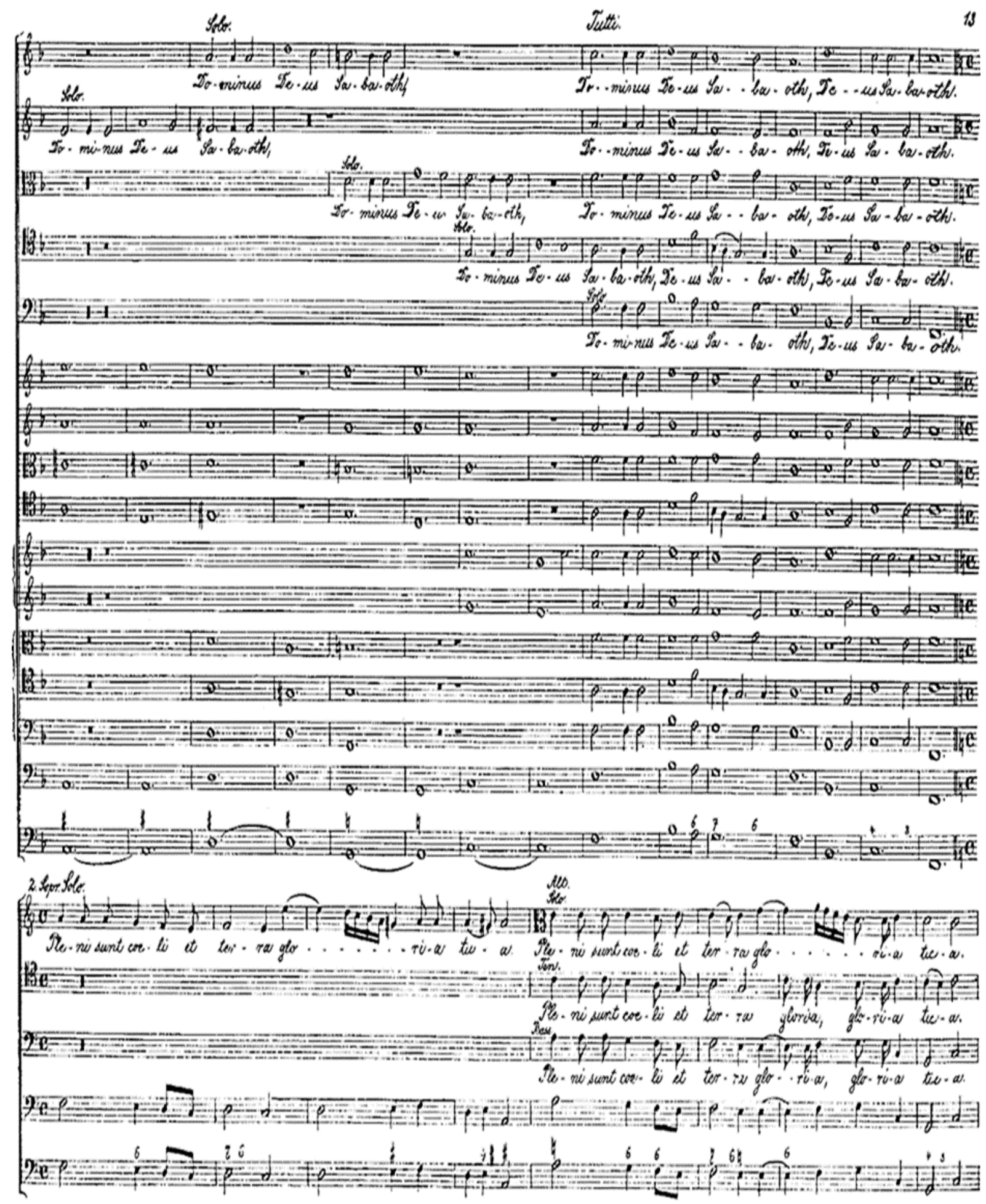

Fig. 2: Compassos 16-38 do Santus da Missa pro defunctis (W11), de Leopoldo I. Fonte: Dietz (1891, p.13).

Acerca desta relação entre Leopoldo e a composição, Aluise Molin, na mesma carta citada acima, diz:

[...] sua inclinação particular é a música. Ele compõe perfeitamente, [...] empregando dias inteiros nela, ele me disse inúmeras vezes, sem nunca se cansar. Vos- 
sa Majestade gasta 60 mil florins para manter uma capela florescente de vozes e instrumentos. (MOLIN, 1661 apud FIEDLER, 1867, p.48). ${ }^{18}$

O interesse de Leopoldo pela música não se resumiu apenas ao seu envolvimento na área da composição, mas incluiu também grandes investimentos na capela imperial. O início do seu reinado foi marcado por uma profunda reorganização da vida musical vienense. Desse modo, na década de 1660, o ambiente de estabilidade e conservadorismo estético do final do reinado de Fernando III deu lugar "a um grande influxo de novas personalidades musicais" (BENNETT, 2013, p.32). ${ }^{19}$ Dentre estes, destacam-se os músicos italianos Antonio Maria Viviani, Carlo Cappellini e Filippo Vismarri, assim como os compositores que chegaram, como veremos mais adiante, para trabalhar na capela pessoal da imperatriz viúva Leonor de Gonzaga-Nevers, como Giuseppe Tricarico, Giovanni Battista Pederzuoli e Antonio Draghi. Draghi, em especial, ganhou muita notoriedade na corte vienense enquanto ainda trabalhava na capela de Leonor, tendo, como consequência, sido escolhido por Leopoldo I, em 1682, para assumir o comando da Hofburgkapelle, posição hierárquica mais alta para um músico na Áustria.

Além da presença desta longa série de músicos italianos em Viena, a conexão musical da Monarquia de Habsburgo com a Itália durante o reinado de Leopoldo I também envolveu a formação sistemática dos principais compositores austríacos no Collegium Germanicum em Roma. O Collegium Germanicum, fundado em 1552, foi, juntamente com o Colégio de Viena, uma das primeiras instituições jesuíticas a adotar o ensino sistemático de música. Apesar da prescrição de Ignácio Loyola vistas acima, a presença de uma longa série de músicos prestigiados, notadamente Giacomo Carissimi (que trabathou como professor e mestre de capela entre 1629 e 1674), fez com que o colégio usufruísse uma excelente reputação quanto aos seus empreendimentos musicais. Durante o período em que Carissimi assumiu o comando das produções musicais do colégio, houve um crescimento substancial na quantidade de músicos profissionais na instituição.

Entre os diversos alunos de Carissimi, destacam-se os austríacos Philipp Jakob Baudrexel e Johann Caspar Kerll. Entretanto, ainda que tanto músicos italianos quanto germânicos fossem contratados pela aristocracia austríaca, via de regra,

[...] a nacionalidade de um compositor definia seus deveres. Os compositores italianos forneciam música dramática (ópera, oratório e cantata), enquanto os austríacos concentravam-se em peças instrumentais, incluindo música de balé (para obras dramáticas), música de teclado, composições litúrgicas e música para os dramas jesuítas. Essa separação de deveres não era inteiramente rigorosa (BENNETT, 2013, p.28).20

\footnotetext{
18 Original: "sua particolare inclinazione è alla Musica. Compone perfettamente, [...] impiegando in essa gionate intiere, m'hà più volte detto, non stancarsi mai d'essa. Spende Sua Maestá pur in questa 60 mil fiorin, e tiene di voci, e stromenti una floridissima Capella" (MOLIN, 1661 apud FIEDLER, 1867, p.48).

19 Original: "an influx of strong new musical personalities" (BENNETT, 2013, p.32).

20 Original: "[...] a composer's nationality defined his duties. Italian composers provided dramatic music (opera, oratorio, and cantata), while Austrians concentrated upon instrumental ensemble pieces, including ballet music (for dramatic works), keyboard music, liturgical compositions, and music for the Jesuit dramas. This separation of duties was not entirely strict" (BENNETT, 2013, p.28).
} 
De acordo com John Hill, Leopoldo foi responsável pela formação de diversos compositores nativos do Sacro Império Romano-Germânico, como Johann Heinrich Schmelzer (1620-1680), Ferdinand Tobias Richter (1651-1711) e Johann Joseph Fux (1660-1741). "Todos esses compositores escreveram música sacra em latim para grandes conjuntos e em estilo grandioso" (HILL, 2005, p.300). ${ }^{21}$

Outra figura da Casa de Habsburgo de grande relevância para o desenvolvimento da música na Áustria foi o tio de Leopoldo I, Leopoldo Guilherme (bispo de Passau, Strassburg, Halberstadt, Olmütz e Breslau). Devido à sua paixão pelas artes, em particular pela ópera, Leopoldo Guilherme passou a ser, especialmente após o fim da Guerra dos Trinta Anos, um dos principais patronos da arte em toda a Europa. Desse modo, o aristocrata austríaco

[...] desempenhou um papel central na atração de músicos italianos para a corte imperial. Dois agentes que serviram ao arquiduque para esse fim foram Friedrich, landgrave de Hessen-Darmstadt, e o jesuíta Theodorico Bechei, ambos mantinham laços especialmente fortes com Roma. Leopoldo Guilherme apoiou jovens músicos italianos em seu serviço, que estudaram no colégio alemão em Roma. (BENNETT, 2013, p.21). ${ }^{22}$

Todavia, apesar desta clara influência da música italiana, a maior parte dos compositores trabalhando em Viena e no resto da Áustria, procuraram adaptar as novas técnicas composicionais provindas da Itália à preferência tipicamente germânica pelo estilo contrapontístico. Portanto, enquanto nas regiões de Nápoles, Veneza e Mântua o stile moderno se desenvolveu essencialmente através da monodia e de composições homofônicas para poucas vozes,

[...] na Alemanha foi o estilo concertante coral que mais se desenvolveu. Temas declamatórios, elaborados à maneira do antigo estilo polifônico, deram forma a uma nova configuração coral. Johann Kaspar Kerll, aluno de Carissimi, foi o líder nessa arte que nunca ganhou muito apoio na Itália. Heinrich Schmelzer, Franz Heinrich Biber, Christoph Strauss e outros também cultivaram essa forma de coral. [...] Até mesmo os italianos trabalhando nas cortes germânicas, como Giovanni Valentini (organista em Viena, 1619), Antonio Bertali (1605-1699), Felice Sances (1600-1679), Stefano Bernardi (c.1575-1638), e outros desenvolveram esse tipo de configuração. (FELLERER, 1961, p.120). ${ }^{23}$

21 Original: "Emperor Leopold nurtured a new generation of native German composers, notably Johann Henrich Schmelzer (ca. 16201680), Johann Caspar Kerll (1627-1693), Ferdinand Tobias Richter (1651-1711), and Johann Joseph Fux (1660-1741). All these court composers wrote Latin-texted church music for large forces in the grandiose style" (HILL, 2005, p.300).

22 Original: "Leopold Wilhelm played a central role in attracting Italian musicians to the imperial court. Two agents who served the archduke for this purpose were Friedrich, landgrave of Hessen-Darmstadt, and the Jesuit Theodorico Bechei, both of whom maintained especially strong ties to Rome. Leopold Wilhelm supported young italians musicians in his service who studied at the German college in Rome" (BENNETT, 2013, p.21).

23 Original: "In Germany it was the concertante choir style that was developed. Declamatory themes, elaborated in the manner of the old polyphonic setting, gave shape to a new choir setting. Carissimi's pupil, Johann Kaspar Kerll (1627-1693), was the leader in this art, which never won much support in Italy. Heinrich Schmelzer, Franz Heinrich Biber, Christoph Strauss, and others also cultivated this choral form. [...] Even the Italians working in German courts, like Giovanni Valentini (organist in Vienna, 1619), Antonio Bertali (1605-1699), Felice Sances (1600-1679), Stefano Bernardi (c.1575-1638), and others developed this form of setting" (KELLERER, 1961, p.120). 
Desse modo, apesar de o fascínio da elite europeia pela ópera italiana ter influenciado profundamente o curso da música em todo o continente, diferentemente da França e da Itália, nas cortes germânicas o contraponto continuou sendo, pelo menos até o início do século XVIII, parte fundamental tanto das composições sacras quanto das seculares.

Ademais, com a vitória das tropas austríacas contra os invasores turcos, em 1683, os gastos com a capela imperial cresceram de maneira constante, chegando a contar em 1705 (ano da morte de Leopoldo I) com o total de 102 musicistas. ${ }^{24}$ Outrossim, nos últimos 12 anos de seu reinado, Leopoldo procurou reformar e repovoar a capela musical imperial, proporcionando, desse modo, uma mudança radical, após um período de certo conservadorismo, no tipo de música produzida em Viena. Segundo Harry White,

A nomeação, nos últimos anos do reinado de Leopoldo, de compositores mais jovens para a corte imperial, incluindo Carlo Agostino Badia (1694), Giovanni Bononcini (1697), Johann Joseph Fux (1698) e Marc'Antonio Ziani (1700), foi uma das principais causas desta impressionante modernização. (WHITE, 2013, p.16). ${ }^{25}$

\section{A capela de Leonor e o estabelecimento do sepulcro em Viena}

Em grande medida, é possível dizer que, durante a primeira metade do reinado de Leopoldo I (particularmente entre 1658 e 1686), a imperatriz viúva Leonor de Gonzaga-Nevers foi uma das figuras mais importantes na patronagem das atividades musicais da corte imperial. Ainda que nos séculos XV e XVI diversos membros da Casa de Habsburgo já desempenhassem papéis de grande relevância no desenvolvimento da música austríaca - principalmente através da patronagem de músicos de destaque da Europa (em especial da Itália) - , foi somente após o fim da Guerra dos Trinta Anos, com a liberação dos recursos da guerra e a transformação da corte imperial em um centro marcadamente cosmopolita, que as produções musicais executadas em Viena começaram a ganhar notoriedade em um nível continental. Dentro deste contexto, o casamento do imperador Fernando III e de Leonor de Gonzaga-Neves, em 1651, fortaleceu ainda mais o processo de italianização da música na Áustria.

Assim como Leopoldo I e Fernando III, Leonor teve uma educação profundamente religiosa, tendo passado a maior parte de sua adolescência no convento de Sant'Orsola, onde desenvolveu seu interesse pela arte e pela música. Por conta desta educação e de seu envolvimento com as principais atividades artísticas da época, a adaptação de Leonor à vida na corte de Viena foi consideravelmente fácil. Segundo Schnitzer-Becker (1993),

Apesar de não parecer excessivamente piedosa aos olhos de seu tempo, Leonor compartilhou com Ferdinando a atitude religiosa, os interesses literários e o amor

\footnotetext{
24 Original: "By 1705, the last years of Leopold's reign, the total number of court musicians had grown to 102" (BENNETT, 2013, p.27).

25 Original: "The appointment in particular of younger composers to the imperial court, including Carlo Agostino Badia (1694), Giovanni Bononcini (1697), Johann Joseph Fux (1698), and Marc'Antonio Ziani (1700) in the closing years of Leopold's reign was the cause of this striking modernization" (WHITE, 2013, p.16).
} 
pela música. Leonor participou de passatempos judiciais, organizou banquetes, favoreceu e assistiu a apresentações teatrais. (SCHNITZER-BECKER, 1993). ${ }^{26}$

Além da patronagem e da organização regular de diversas execuções musicais dentro e fora da corte, Leonor também ficou conhecida na Áustria por suas habilidades como soprano. Ainda que, por conta da proibição da participação de mulheres nos palcos e nas igrejas, a monarca italiana não tivesse a permissão de se apresentar diante de grandes públicos, a sua presença em produções mais íntimas pôde ser observada com alguma frequência. De fato, ao levar-se em consideração que muitos membros da dinastia de Habsburgo se destacaram durante o século XVII pelo envolvimento regular com algum tipo de prática musical, a participação de Leonor em alguns empreendimentos musicais deixa de ser surpreendente.

Entretanto, apesar deste envolvimento da imperatriz na vida musical vienense durante o reinado de Fernando III, foi principalmente após a morte de seu marido, em 1657, e da coroação de seu enteado Leopoldo I, em 1658, que a aristocrata italiana passou a exercer um papel verdadeiramente significativo no desenvolvimento da música austríaca. Ainda que possa parecer contraditório, este crescimento da importância de Leonor estava relacionado ao fato de que, nos séculos XVI e XVII,

[as] grandes famílias costumavam atribuir até um quinto do valor de suas propriedades em dotes, como forma de criar vínculos com outras grandes famílias; a taxa de juros sobre este montante proporcionava um usufruto que permitia à noiva cobrir seu custo de vida. Na viuvez, a soma total poderia ser reapropriada por ela. (HUFTON, 2006, p.15) ${ }^{27}$.

Dentro desse contexto, o recebimento de cerca de 200 mil florins por ano, aos quais 21.452 eram despendidos com empreendimentos musicais diversos, permitiu que Leonor estabelecesse sua própria corte pessoal em uma das alas do Palácio Imperial de Hofburg, em Viena, incluindo uma nova capela musical com 20 músicos, um mestre de capela, um copista, um luthier e um tocador de fole. Segundo Deisinger (2016, p.171), "a fundação de uma corte para uma imperatriz viúva era comum naqueles dias e os pré-requisitos legais para isso já haviam sido estabelecidos no contrato de casamento". ${ }^{28}$ Ademais, o estabelecimento desta corte pessoal só foi possível por conta do bom relacionamento entre o novo imperador e Leonor, o que pode ser atestado pelo seguinte trecho da carta escrita por Molin em 1661: "A imperatriz Leonor governa a si mesma

\footnotetext{
26 Original: "Pur non apparendo eccessivamente pia agli occhi del suo tempo, Eleonora condivideva con Ferdinando l'atteggiamento religioso, gli interessi letterari e l'amore per la musica. Eleonora partecipava ai passatempi di corte, organizzava banchetti, favoriva e presenziava a rappresentazioni teatrali" (SCHNITZER-BECKER, 1993).

27 Original: "[the] great families could put up to a fifth of the value of their estates into dowries as a way of creating links with other great families; the interest on the sum provided a usufruct enabling the bride to meet her living costs. In widowhood the whole sum could become hers to reappropriate" (HUFTON, 2006, p.15).

28 Original: "the foundation of a court for a widowed empress was usual in those days and the legal prerequisites for this had already been established in the marriage contract" (DEISINGER, 2016, p.171).
} 
com a máxima prudência e é amada pelo imperador, estimada como mãe" (MOLIN, 1661 apud FIEDLER, 1867, p.53). ${ }^{29}$

Assim que sua corte foi fundada, Leonor convidou Giuseppe Tricarico para assumir o cargo de mestre de capela (posição que o compositor ocupou até 1662). Tricarico, que havia estabelecido uma boa reputação em Roma e Ferrara entre as décadas de 1640 e 1650, teve então a incumbência de recrutar oito músicos italianos para acompanhá-lo em sua nova jornada; entre eles, foram escolhidos Alessandro Riotti, Jacomo Venturini e seu irmão, Antonio Tricarico. No começo da segunda metade do século XVII, o nome de Giuseppe Tricarico havia se tornado amplamente conhecido entre os membros da Monarquia de Habsburgo por conta, em grande medida, da presença de uma de suas composições (intitulada Crucifixus) no prestigiado livro Musurgia Universalis, escrito pelo jesuíta alemão Athanasius Kircher em 1650. Em seu livro, “Kircher descreve Tricarico como um excelente e extremamente talentoso compositor e seu Crucifixus como uma excelente obra de arte" (DEISINGER, 2007, p.46-47). 30

Apesar da curta estadia do compositor em Viena (aproximadamente seis anos), a elaboração de três obras sacras dramáticas executadas entre 1660 e 1662 teve um impacto significativo para o rumo da música sacra na Áustria..$^{31}$ Isto pois essas peças deram início a uma nova tradição, quase ininterrupta, de apresentações anuais no Palácio Imperial de Hofburg. A partir de então, duas apresentações deste novo gênero dramático, que ainda no século XVII passou a ser intitulado com nomes distintos, como sepulcro, azione sacra, azione sepolcrale e rappresentazione sacra, começaram a ser realizadas todas as Quintas e Sextas-Feiras Santas, em lembrança à morte de Cristo. Enquanto nas Quintas-Feiras Santas os sepulcros realizados na capela de Leonor continham um cenário relativamente simples, contando, em muitos casos, apenas com a escultura do Santo Sepulcro, nas Sextas-Feiras Santas, as apresentações realizadas na Hofburgkapelle dispunham, além da escultura utilizada no dia anterior, de pinturas de fundo sofisticadas, ilustrando o tema do libreto.

Este novo gênero musical, apesar de ser, assim como o oratório, um tipo de obra sacra dramática cantada em italiano, se diferenciava de outras produções da época pelo uso extensivo de personagens alegóricos, figurinos e cenários; pela limitação a temas relacionados à Paixão e Crucificação de Cristo; pela composição em uma única parte estrutural (ao contrário da habitual divisão do oratório em duas seções) e pela escassez de grandes momentos de ação dramática (em decorrência de seu caráter essencialmente descritivo e reflexivo).

Para Robert Kendrick, o estabelecimento do sepulcro, no inverno de 1660, estava relacionado não somente a questões puramente estéticas e religiosas, mas também à

Original: "L'Imperatice Leonora predetta si governa con somma prudenza, et è dall'Imperatore amata, stimata come Madre. Ella non molto s'inferisse nel governo, e mostrando di niente pretende, tutto per il più meritamente ottiene. Sà incontrar il genio di Sua Maestà, e rendersela grata, hà introdutto Oratorij in Musica, e fa venir Predicatori Italini de più celebri, largamente regallandoli, con che più frequentemente gode la conversatione di Sua Maestà" (MOLIN,1661 apud FIEDLER, 1867, p.53).

30 Original: "Kircher bezeichnete Tricarico als exzellenten und äußerst begabten Komponisten und dessen Crucifixus als ein ganz ausgezeichnetes Kunstwerk" (DEISINGER, 2007, p.46-47).

31 Apenas a partitura da peça intitulada La Gara della Misericordia e Giustizia, de 1661, foi preservada. 
necessidade dos membros da Casa de Habsburgo, após o período de transição imperial entre 1657 e 1658, de estabelecerem novas tradições capazes de confirmarem o poder de Leopoldo I e de sua madrasta aos olhos da nobreza vienense. Os sepulcros compostos por Tricarico para a corte de Leonor, por exemplo, apesar de serem consideravelmente mais simples e íntimos do que aqueles realizados durante as Sextas-Feiras Santas na capela principal de Hofburg, possibilitaram a demonstração da força financeira e da sensibilidade religiosa da imperatriz viúva para um círculo restrito, porém imponente, de convidados.

Ao longo do reinado de Leopoldo I, as execuções dos sepulcros tornaram-se cada vez mais reconhecidas internacionalmente, principalmente devido à presença de inúmeros embaixadores e diplomatas de toda a Europa, que, após testemunharem as apresentações, relataram o alto nível de sofisticação das atividades artísticas na Áustria. Entretanto, a performance do sepulcro de 1684 acabou se tornando motivo para uma polêmica entre a imperatriz viúva e o núncio papal (cardinal Francesco Buonvisi). Isto pois Buonvisi decidiu boicotar as atividades organizadas por Leonor após se sentir ofendido pela decisão da imperatriz viúva em destinar o melhor lugar da capela ao duque de Lorraine, Carlos V, obrigando, desse modo, o cardinal a sentar-se em uma posição menos privilegiada para acompanhar o sepulcro (Le Lagrime più giuste, de Pederzoli). Em uma missiva ao secretário de Estado do Vaticano, cardeal Alderano Cybo, Buonvisi relata:

Eu devo defender vigorosamente minha [dignidade do cardeal] contra os ataques da imperatriz Leonor, que os repete com o consentimento tácito do imperador. [...] E agora mais uma vez a imperatriz deu um lugar mais alto ao duque, pois no oratório na Quinta-Feira Santa, eles [a realeza] estavam na frente do sepulcro, [...] e se eu tivesse ido, teria sido colocado em um banco lateral. (BUONVISI, 1684 apud KENDRICK, 2019, p.199). ${ }^{32}$

Ao observarmos o decurso desta polêmica, podemos atestar como o sepulcro acabou se tornando um evento de tal importância dentro da corte imperial, que um detalhe, aparentemente supérfluo, como a posição do assento de uma figura de destaque, se transformou em um escândalo de nível internacional. Do mesmo modo, por meio de uma segunda carta de dez páginas, onde o núncio papal afirma que "a imperatriz viúva sempre demanda mais homenagens opulentas do que o próprio imperador" (BUONVISI, 1684 apud KENDRICK, 2019, p.199), 33 confirmamos o papel fundamental de Leonor na patronagem e organização de grandes produções artísticas durante o reinado de Leopoldo I.

\footnotetext{
32 Original: "Di esser pronto a fi nir qui i miei giorni, bisognerà difenderla [his dignity] con vigore contro gli attacchi dell'imperatrice Eleonora, che asserice di farli col tacito consenso dell'Imperatore. [...] et hora I'Imperatrice ha dato di nuovo luogo più nobile nella sua cappella al sig. Duca, e nell'Oratorio del Giovedì Santo accanto il Sepolcro, [...] e se io ci fossi andato, non ci sarebbe intervenuto S.A., ma sarei stato sopra un banco per fi anco, come è lo stile" (BUONVISI, 1684 apud KENDRICK, 2019, p.199).

33 Original: "Dapoi I'Imperatrice Vedova, che sempre desidera ossequij maggiori di quelli, che si prestano all'Imperat.re" (BUONVISI, 1684 apud KENDRICK, 2019, p.199).
} 


\section{Considerações finais}

Ainda que outros imperadores, em especial Fernando III, já tivessem mostrado interesse pela música sacra, Leopoldo I foi, inegavelmente, o monarca austríaco que mais se envolveu com as atividades musicais do Sacro Império Romano-Germânico, sendo também o compositor mais prolífico da história da dinastia de Habsburgo. Entretanto, este comprometimento público do imperador com a música não agradou a todos os corsões de Viena. Segundo o embaixador veneziano Aluise Molin: "[...] alguns, no entanto, gostariam de ver essa aplicação à música menos evidente em Vossa Majestade. Para deixá-lo mais focado à negociação e a disposições mais magnânimas" (MOLIN, 1661 apud FIEDLER, 1867, p.49). ${ }^{34}$

De modo semelhante, ainda que muitos acreditassem que a educação marcadamente religiosa de Leopoldo I fosse uma vantagem para a administração de seu governo, outros, como o embaixador Marino Giorgi, diziam:

Falta-lhe vigor no comando, franqueza nas resoluções, entusiasmo em fazê-las e ousadia em se aplicar às maiores e mais notáveis operações. Eles desertam dos defeitos de um espírito despertado pela educação generosa, inadequada para a coroa e cetro. (GIORGI, 1671 apud FIEDLER, 1867, p.127). ${ }^{35}$

Todavia, apesar de todos estes protestos, o reinado de Leopoldo foi marcado pela intensificação contínua da patronagem de novos músicos e compositores, principalmente de origem italiana, e pela expansão da capela imperial, gerando, em consequência, uma profunda renovação das produções musicais vienenses. De modo semelhante, ainda que outras imperatrizes viúvas já tivessem mostrado interesse na patronagem da música, o nível de influência exercido por Leonor de Gonzaga-Nevers nos empreendimentos musicais em Viena nunca havia sido observado anteriormente e, em grande medida, nunca conseguiu ser igualado novamente. Segundo Deisinger (2016, p.179), "com seus músicos, Leonor se tornou um foco da vida cultural na corte vienense. Ela organizou concertos e performances de obras musicais dramáticas e teve festivais religiosos adornados com músicas comemorativas". ${ }^{36}$ Indubitavelmente, este interesse dos membros da Casa de Habsburgo pela música, e em especial pela música sacra, foi crucial para a formação de Viena como um dos principais centros musicais da Europa.

Assim sendo, é surpreendente, levando em consideração a importância da capital austríaca para a história da música ocidental, que a historiografia sobre o barroco vienense seja tão escassa. A maior parte da literatura publicada sobre a vida musical em Viena, escrita tanto por pesquisadores nativos da Áustria quanto de outras partes do

\footnotetext{
34 Original: "Alcuni però bramerebbero, che quest' applicatione alla Musica fosse men valida in Sua Mtá., per lasciarla maggiore al negotio, et à più magnanime dispositioni" (MOLIN, 1661 apud FIEDLER, 1867, p.49).

35 Original: "Li manca vigore nel commando, franchezza nelle rissolutioni, ardone nell'essequirle, et ardire nell' applifgiarsi ad operationi magvanime, et cospicue; Seaturiscono li difetti da spirito destituto d'educatione generosa, non addatata alle Corone, et alli Scetri" (GIORGI, 1671 apud FIEDLER, 1867, p.127).

36 Original: "with her musicians, Eleonora became a focus of cultural life at the Viennese court. She arranged concerts and performances of musical dramatic works and had religious festivals adorned with celebratory music" (DEISINGER, 2016, p.179).
} 
mundo, tem como objeto de estudo o período entre o advento do Josefismo e o fim da Segunda Guerra Mundial, ou seja, entre a primeira e a segunda Escola de Viena (de Haydn a Schoenberg). De acordo com Harry White (2013, p.11),

A história - incluindo a história da música - inseriu um véu sobre o barroco vienense. [...] Não é de forma alguma um estado de coisas excepcional ler a história monumental (e relativamente recente) da música ocidental de Richard Taruskin, por exemplo, um relato estupendamente detalhado da música antiga que, no entanto, consegue eclipsar todo o barroco vienense, apesar da magnitude evidente e proeminência da música na corte imperial durante esse período. ${ }^{37}$

\section{Referências bibliográficas}

BENNETT, Lawrence. The Italian Cantata in Vienna: Entertainment in the Age of Absolutism. Indiana: Indiana University Press, 2013.

BIRELEY, Robert. The Counter-Reformation prince: anti-Machiavellianism or Catholic statecraft in early modern Europe. Chapel Hill: The University of North Carolina Press, 1990.

CORETH, Anna. Pietas Austriaca. Indiana: Purdue University Press, 2004.

DEISINGER, Marko. Eleonora II und die Gründung ihrer Hofkapelle; Ein Beitrag zur Geschichte des kulturellen Lebens am Wiener Kaiserhof. Frühneuzeit-Info, v. 18, p. 4548, 2007.

DEISINGER, Marko. The Music Chapel of Empress Eleonora II. Source-related Difficulties in Researching the History of an Italian-dominated Institution in Vienna (1657-1686). Athens Journal of Humanities \& Arts, v. 3, Issue 3, p. 171-180, 2016.

FELLERER, Karl Gustav. The history of catholic church music. Trad. F. A. Brunner. Minesota: Helicon Press, 1961.

FIEDLER, Joseph von (ed.). Die Relationen der Botschafter Venedigs über Deutschland und Österreich im siebzehnten Jahrhundert/2: K. Leopold I. Viena: KaiserlichKönigliche Hof- und Staatsdruckeri, 1867.

HILL, John Walter. Baroque music: music in Western Europe, 1580-1750 (The Norton Introduction to Music History). New York: W. W. Norton \& Company, 2005.

37 Original: "History - including music history - has draw a veil over the Viennese Baroque. [...] It is by no means an exceptional state of affairs to read in Richard Taruskin's monumental (and comparatively recent) history of western music, for example, a stupendously detailed account of early music which nevertheless manages to eclipse the Viennese Baroque in its entirely, despite the self-evident magnitude and prominence of music at the imperial court during this period" (WHITE, 2013, p.11). 
HOLLER, Marcos. Os jesuítas e a música no Brasil colonial. Campinas: Ed. Unicamp, 2010.

HUFTON, Olwen. Every tub on its own bottom: funding a Jesuit College in early modern Europe. In: O'MALLEY, J.; BAYLEY, G.; HARRIS, S.; KENNEDY, T. (org.). The Jesuits II: Cultures, Sciences, and the Arts, 1540-1773. Toronto: University of Toronto Press, 2006. p. 5-23.

INGRAO, Charles W. The Habsburg Monarchy, 1618-1815 (New Approaches to European History). Cambridge: Cambridge University Press, 2005. Edição Kindle.

KENDRICK, L. Robert. Fruits of the cross: Passiontide music theater in Habsburg Vienna. California: University of California Press, 2019.

POTTER, Pamela M. A mais alemã das artes: musicologia e sociedade da República de Weimar ao fim da era nazista. Trad. R. Patriota. São Paulo: Perspectiva, 2015.

SCHNITZER-BECKER, Rotraut. Dizionario Biografico degli Italiani. Roma: Treccani, 1993. v. 42. Disponível em: https://www.treccani.it/enciclopedia/eleonora-gonzaganevers-imperatrice_(Dizionario-Biografico). Acesso em: 20 jan. 2020.

SOMERSET, H. V. F. The Habsburg Emperors as Musicians. Music \& Letters, Oxford University Press, v. 30, n. 3, p. 204-215, 1949.

WEAVER, Andrew. Music in the Service of Counter-Reformation Politics: The Immaculate Conception at the Habsburg Court of Ferdinand III (1637-13657). Music \& Letters, v. 87, n. 3, p. 361-378, 2006.

WEAVER, Andrew. Sacred Music as Public Image for Holy Roman Emperor Ferdinand III Andrew H. Weaver Representing the Counter-Reformation Monarch at the End of the Thirty Years' War. New York: Routledge, 2012.

WHITE, Harry. Johann Joseph Fux and the Musical Discourse of Servitude. In: ERHARDT, T. (org.). Sakralmusik im Habsburgerreich 1570-1770. Viena: Österreichische Akademie der Wissenschaften, 2016. 